\title{
Corrigendum to "Metastatic Renal Cell Carcinoma with Level IV Thrombus: Contemporary Management with Complete Response to Neoadjuvant Targeted Therapy"
}

\author{
Abhishek Bhat $\mathbb{D D}^{1}{ }^{1}$ Bruno Nahar, ${ }^{1}$ Vivek Venkatramani, ${ }^{1}$ Indraneel Banerjee, ${ }^{1}$ \\ Oleksandr N. Kryvenko, ${ }^{1,2,3}$ and Dipen J. Parekh ${ }^{1,3}$ \\ ${ }^{1}$ Department of Urology, University of Miami Miller School of Medicine, Miami, FL, USA \\ ${ }^{2}$ Department of Pathology and Laboratory Medicine, University of Miami Miller School of Medicine, Miami, FL, USA \\ ${ }^{3}$ Sylvester Comprehensive Cancer Center, University of Miami Miller School of Medicine, Miami, FL, USA \\ Correspondence should be addressed to Abhishek Bhat; axb1722@med.miami.edu
}

Received 21 October 2019; Accepted 22 October 2019; Published 20 November 2019

Copyright (@) 2019 Abhishek Bhat et al. This is an open access article distributed under the Creative Commons Attribution License, which permits unrestricted use, distribution, and reproduction in any medium, provided the original work is properly cited.

In the article titled "Metastatic Renal Cell Carcinoma with Level IV Thrombus: Contemporary Management with Complete Response to Neoadjuvant Targeted Therapy" [1], the last sentence in the Abstract should be corrected from "We describe a case of a right-sided metastatic RCC with Level IV thrombus initially managed with Pazopanib followed by Nivolumab and Adalimumab followed by cytoreductive nephrectomy and IVC thrombectomy in the post-targeted therapy setting with complete curative response" to "We describe a case of a right-sided metastatic RCC with Level IV thrombus initially managed with neoadjuvant targeted therapy followed by cytoreductive nephrectomy and IVC thrombectomy in the post-targeted therapy setting with complete curative response".

\section{Reference}

[1] A. Bhat, B. Nahar, V. Venkatramani, I. Banerjee, O. N. Kryvenko, and D. J. Parekh, "Metastatic renal cell carcinoma with level IV thrombus: contemporary management with complete response to neoadjuvant targeted therapy," Case Reports in Urology, vol. 2019, Article ID 7102504, 5 pages, 2019. 


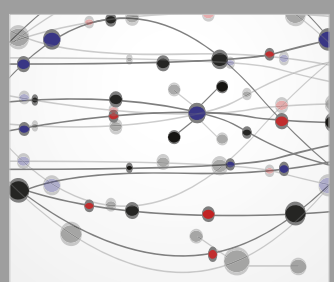

The Scientific World Journal
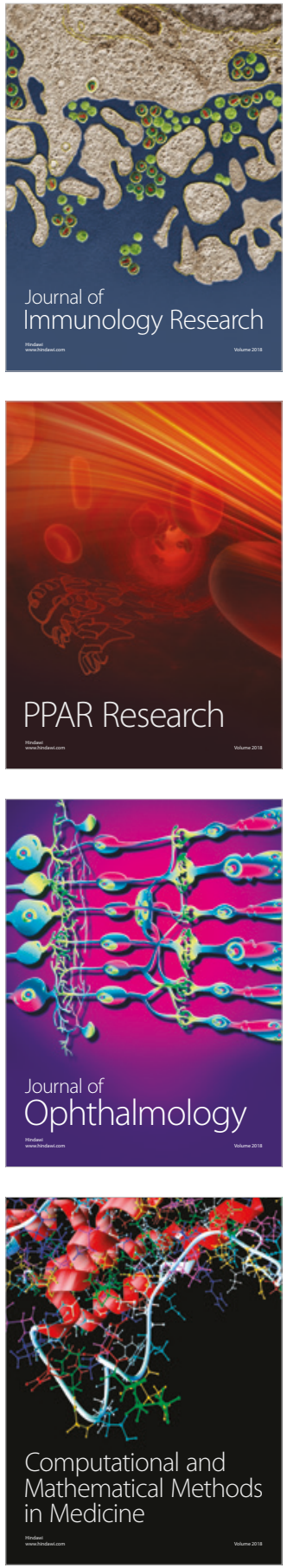

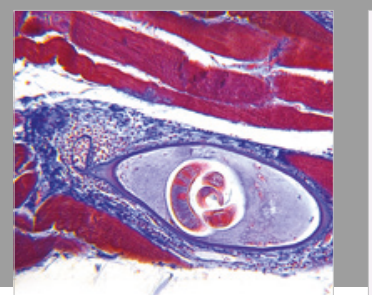

Gastroenterology Research and Practice

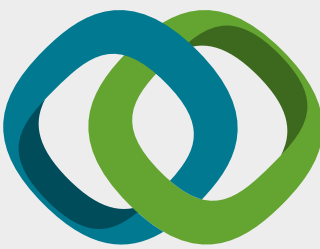

\section{Hindawi}

Submit your manuscripts at

www.hindawi.com
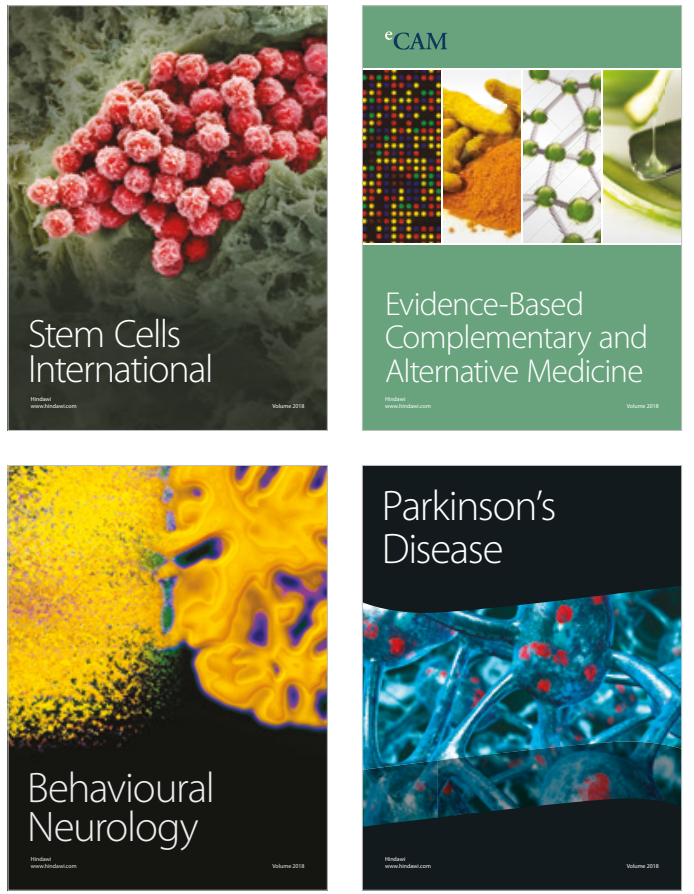

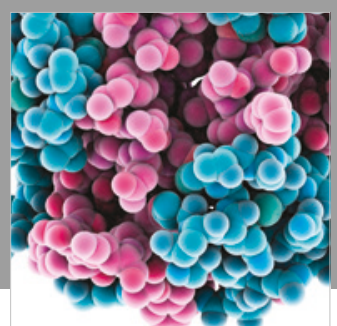

ournal of

Diabetes Research

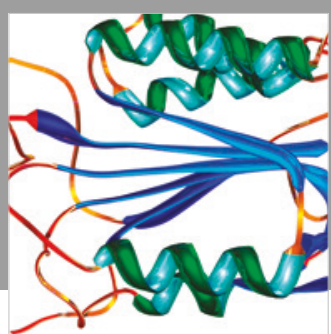

Disease Markers
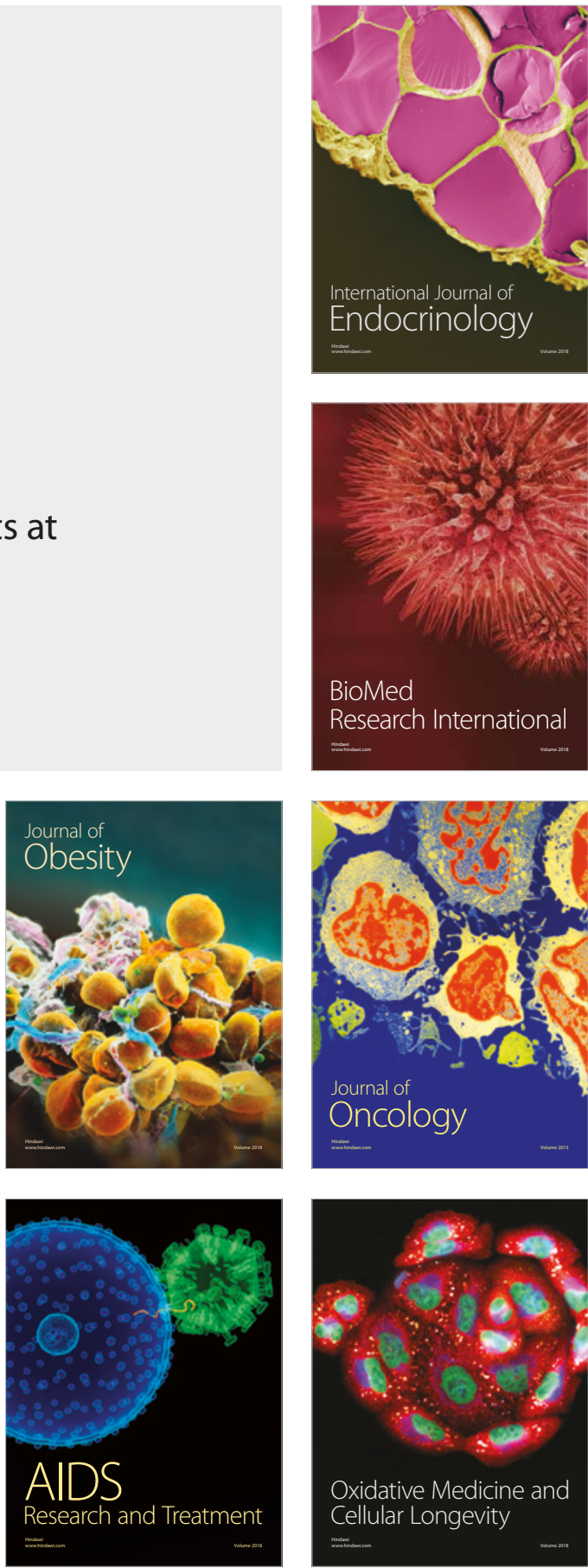